\title{
Exploring the impact of body-worn video on the everyday behaviours of police officers
}

The Police Journal: Theory, Practice and Principles

(C) The Author(s) 2021

(c) (i) 8

Article reuse guidelines: sagepub.com/journals-permissions DOI: 10.1 I 77/0032258X2 I 1000834 journals.sagepub.com/home/pjx

\section{Karen Harrison $(\mathbb{D}$}

Lincoln Law School, College of Social Science, University of Lincoln, Brayford Pool, Lincoln, UK

\section{Xavier L'Hoiry}

Department of Sociological Studies, University of Sheffield, Sheffield, UK

\section{Simone Santorso}

Department of Criminology and Sociology, Faculty of Arts Cultures and Education, University of Hull, Hull, UK

\begin{abstract}
The use of body-worn video in Police Forces in England and Wales is not new. On the whole, evaluations have been positive, although, there is little evidence regarding how beneficial the cameras can be in terms of how they impact on the everyday behaviours of police officers. This article looks at how the implementation of BWV into one police force in England impacted on the behaviour of those officers who wore the technology. While the dominant view is positive, concerns as to privacy infringements and the use of BWV footage as a potential tool for supervisory surveillance emerged.
\end{abstract}

\section{Keywords}

Body-worn video, impact on policing behaviour

\section{Introduction}

The use of body-worn video (BWV) in Police Forces in England and Wales is not new, with the technology also prevalent in the United States (Miller, 2014), Spain (Coudert

\section{Corresponding author:}

Karen Harrison, Lincoln Law School, College of Social Science, University of Lincoln, Brayford Pool, Lincoln LN6 7TS, UK.

Email: karenharrison@lincoln.ac.uk 
et al., 2015), India (Kumar, 2018), Israel (Kamisher, 2017), Mexico (Kahn, 2015) and more recently France (France 24, 2019). Other countries, including Australia (Clare et al., 2019) and Belgium are considering its use following a series of trials (Coudert et al., 2015) with Italy, Sweden, Finland and the Netherlands also considering its benefits (Laming, 2019). On the whole, evaluations have been positive (Spencer and Cheshire, 2017), with benefits including an improvement in citizen behaviour (Demir et al., 2020; Jennings et al., 2014), a reduction in stop and search (Ready and Young, 2015), an increase in cooperation with the police (Ariel, 2016), a reduction in use of force incidents (Cubitt et al., 2017), a decrease in public complaints (Ariel et al., 2015, 2016a), and an increase in guilty pleas as a result of better evidence capture (College of Policing, 2014). Other positives include a reduction in crime rates for certain types of crime and thus a consequential reduction in court costs (Cubitt et al., 2017). More cautious and sometimes conflicting research however, has noted how wearing BWV can increase the risk of assault against an officer, has no effect on police use of force (Ariel et al., 2016b) and may in fact have little to no effect on civilian complaints (Yokum et al., 2017).

Other research has looked at how the public and police officers perceive BWVs, with there being little consensus in terms of officers' perceptions. Gaub et al., for example, found that while officers in Phoenix, Arizona were negative about having the cameras, those in Tempe, Arizona were more favourable, while officers in Spokane, Washington, gave both positive and negative views (Gaub et al., 2016). Perceptions of the benefits of BWV by the public have, however, largely been more favourable, including the belief that the use of the cameras will improve citizen and police behaviour and enhance evidence gathering (Laming, 2019).

Despite this plethora of research, there is little evidence regarding the impact of BWV on the everyday professional behaviours ${ }^{1}$ of those police officers who wear them (Cubitt et al., 2017; Laming, 2019). One of the few studies that has looked at how the cameras impacted on police officer behaviours, found that officers with BWV, in Florida, largely relied on less intrusive methods to resolve incidents, continued to interact with the public but overall were rather pessimistic about the usefulness of the technology (Headley et al., 2017). In an attempt to add to this growing literature base, this article briefly looks at the positive impacts of having BWV in policing and considers, in more detail, how its use in one police force in England has impacted the everyday behaviours of those officers who were tasked with wearing the technology.

\section{Background and methodology}

The data used in this article were collected as part of a larger qualitative project, funded by the N8 Policing Research Partnership ${ }^{2}$ and the subject police force, which explored the policy, training and implementation of BWV in that police area. The data collection for the implementation of BWV technology took place during the period of May 2019March 2020. In order to gain as much insight as possible, the research team opted for a triangulated (Denzin, 1970) or multi-method (Bryman, 2012) assessment design, including ethnographic observations, a focus group, a survey and follow up interviews. Eight ethnographic observations were undertaken, with the 'ride-along' scheme used to 
facilitate these. The observations were used, largely to introduce the researchers into the workings of BWV practice in the police area, although reference to some of our ethnographic notes is made in the analysis below. Following the observations, a focus group, with five officers, was used to help design the survey instrument. The officers were a mixture of age, job role and service length and were asked to express general opinions about the implementation and their use of BWV. The survey was sent to approximately 800 police officers, with 123 responses received. Containing 18 questions, the survey explored the perceptions and understanding of the topics which emerged during the focus group with a specific interest on officers' views before and after the implementation of BWV. Participants of the survey were asked whether they would be willing to share further views on BWV through an interview. In total 20 people agreed to do this, and, according to the principle of saturation ${ }^{3}$ (Glaser and Strauss, 1967) the research team followed up with a sample size of 10 participants. These participants were selected based on their job roles, location in the police force area, length of service in the police and gender. We interviewed five men and five women. We were able to achieve a cross section of experience and length of service, ranging from less than 2 years to over 20 years. It is acknowledged that interviewing 10 people cannot be considered as fully representative of opinion across the force. What is offered here should, therefore, be considered as a snapshot of views taken during a specific time period. To help retain anonymity, no police ranks are mentioned, and all officers are referred to as they/their so as to avoid attribution of gender. The analysis which follows synthesises these various data to present the views of police officers and staff concerning the impact of BWV on their everyday behaviours and working practices. This article mainly relies on interviews to better reflect their perception of the new technology, in an attempt to provide an 'emic' (Farrell and Hamm, 1998) perspective on the impact of the BWV on their behaviour.

\section{The positive impact of BWV in policing}

To help with data analysis, officers were classified into three groups: patrol and response officers; those working in investigation, prisoner processing or protecting vulnerable people (PVP) units; and disclosure officers. Despite the ambiguity found by Gaub et al. (2016), the overriding majority of our officers were positive about the introduction of BWV, describing it as 'crucial' (Interview 7) and 'vital' (Interview 1). All patrol and response officers who were asked whether if given the option they would wear the camera said yes. All those working in either investigation, prisoner processing or in PVP units said they would also choose to have the camera/footage if given the option. Of the three groups, disclosure officers were the most negative, but even within this group many were still able to cite some positive aspects.

Confirming previous research (College of Policing, 2014), the dominant view from all officers was that the main benefit of having BWV was an increased ability to record and therefore capture evidence. This included but was not limited to suspect, victim and witness statements, admissions of guilt, damage to property, injuries to victims, the behaviour and demeanour of people and the identification of additional witnesses. BWV was also used to capture whether procedures had been followed correctly such as those 
required in searches, taser deployment and arrest. In the survey, participants were asked to identify up to three benefits of BWV (Q10). The statement selected by the most participants was 'BWV improves my ability to gather evidence', which was selected by $89.3 \%(n=108)$ of those who responded. In terms of the benefits of being able to capture such evidence, one disclosure officer stated, 'a picture is worth more than a thousand words, if you can see something happening, the written word doesn't adequately describe it' (Interview 2). This view was also shared by those working in prisoner processing, with one officer giving the below example:

I remember having a case a couple of months ago where several people had been arrested for a street fight, so a drunken night out, and one of them pulled a pool cue from his pocket and tried to hit somebody else with it, and the other person had punched the other guy in the face, and all this had happened whilst the other guy was talking to the police officer, so the whole thing was on body worn cameras, so we were able to take one look at the footage and in the end we didn't have to interview them because the full offence was made out. There was no way to get around the fact that he's pulled a pool cue and somebody else tried to hit him, so it made our job so much easier because it was just a case of here's the body worn footage (Interview 4).

Another explained how reviewing the footage as part of a handover package revealed evidentially much more than a statement or a handover sheet could because 'we can see for ourselves what's been said and the demeanour of people' (Interview 5). Those officers who captured the footage often found watching it back useful when making their statements, especially when it had been 'a particularly stressful job or something where you can't remember ... it's good for significant comments' (Interview 9).

The footage was also deemed to be incredibly important for victimless prosecutions, especially where there was evidence of similar incidents which had been recorded and were still on file. Having evidence of several incidents which included the victim's injuries, demeanour and full account was therefore seen as vital. In such instances, footage was also viewed as important as it could create what interviewees viewed as the 'true' picture for a jury to see:

how scary or abusive that situation has been, and [they] can directly see the impact that's had, and often that's possibly where body worn comes into its own because there's a world of difference between a sanitised statement saying person $\mathrm{x}$ approached me, raised his right hand with a clenched fist, and swung it towards my face, to seeing a six foot tall guy, three times wider than the police officer, snarling and throwing his fist forwards. It feels very different, and that's where the big impact comes in (Interview 4).

In some circumstances the footage was additionally seen as useful to actually help identify who was innocent, rather than who was guilty.

\section{BWV and its impact on officer's behaviour}

Acknowledging that less is known in the literature about how the wearing of BWV affects an officer's everyday behaviour (Laming, 2019), we were keen to ensure that 
this element was included in our survey instrument. Question nine therefore asked participants whether wearing the camera had changed their own behaviour. In particular they were asked to select up to three statements from a list of seven; with the seventh being an 'other' option which then asked for more detail. The six options which officers could have selected included:

- When wearing BWV, I speak to people in exactly the same way as before.

- I feel BWV negatively affects my privacy and work routine.

- When wearing BWV, I am more inclined to report an assault against me.

- When wearing BWV, I am more likely to give a formal sanction rather than just a warning.

- Wearing BWV makes me less likely to use force against a member of the public even when appropriate.

- I feel more confident having BWV because it protects me against public complaints.

Through the ethnographic observations, the focus group, other survey questions and the follow up interviews, we were also able to glean how the cameras had affected officer behaviour. Sometimes the change in behaviour was minimal, other times it was more marked, with there being examples of how this change was both positive and negative.

Communicating with and being accountable to the public. When answering question nine of the survey in relation to behavioural change, the two most common responses related to an officer's interaction with the public. The statement most commonly selected was 'When wearing BWV, I speak to people in exactly the same way as before' $(76.3 \%(\mathrm{n}=71)$ ), indicating that BWV had a neutral to positive impact on the relationship between the police and members of the public. From the interviews, officers gave mixed examples of how the cameras had impacted on their interaction with the public. One officer who had previously been a community beat manager spoke positively about the technology:

They were incredibly useful for letting other people know you were recording, which instantly changes how people act around you, and also it's quite a good conversation opener, especially in my role as a neighbourhoods bobby where sometimes you'd be on a foot patrol on the streets and you want to talk to people, and suddenly you've got a mother with three kids, and the three kids all see themselves in the camera and start waving at it, and they clearly just want to talk and have a play with the camera, so it's something that makes you a little bit less intimidating (Interview 4).

Another officer, however, was less optimistic, explaining how having the cameras sometimes made their job harder, particular with regards to breaking down barriers during police-citizen interactions:

If you're going to somebody who is reluctant to speak to the police in the first place, sometimes having that camera there can be a bit of a wall between you because we're not allowed to go covert (Interview 8). 
Furthermore, in relation to concern that all footage was open to be seen by supervisors (see below), the same officer explained that where they once would have let children play with the cameras, their behaviour regarding this had now changed:

I mean I've had kids ... playing with my camera and turning it on, turning it off again, and you never once thought that was going to be a problem because it's footage that's going to disappear... now I wouldn't be letting a kid press the record button on my camera so they can wave at it and keep them entertained for ten minutes because I'd think that is going to put me under scrutiny (Interview 8).

Although we found that interactions with the public had largely stayed the same, supporting the findings in Florida (Headley et al., 2017), some officers did feel that wearing the cameras made them more accountable to the public. Question 10 of the survey asked participants to identify up to three benefits of having BWV and $41.3 \%$ ( $\mathrm{n}=$ 50 ) identified increased accountability. This was a view echoed in the interviews as well. Some officers stated that when they switched their camera on, it made them feel more professional and put them into 'policing mode'. Another spoke about how the cameras generated a sense of self-policing: 'While you've got that camera on, you're not going to do anything that's going to let you down' (Interview 9). This echoes the findings of Ariel et al. who argue that BWV encourages police officers to 'respond with what most of us would deem a more accountable, professional approach, demonstrating fairness, dignity, and respect' (Ariel et al., 2018: 10). This was again emphasised during one of the observations when one supervising officer commented that they liked BWV because they believed that it had raised the professional standards of officers.

Perhaps a negative aspect to this new layer of accountability however, was that some officers expressed concerns that BWV footage was increasingly being used as part of appraisals and/or supervision meetings. This issue was raised by both interview and survey participants, with the view being one of fear and concern. One survey participant, for example, said 'I am aware that the BWV footage has been dip sampled which has made me wary about who else views it and why' (Survey - Question 15). Others said that this concern had made them change their behaviour somewhat:

I feel like I spend more time trying to speak people round to give evidence etc. even when it is obvious, they won't. I feel this is because it is on camera it has to be justified better (Survey - Question 15).

Another commented how they 'feel like big brother is watching us' (Survey Question 15).

Other officers had a more balanced view on footage being used in supervision. One stated:

I can understand officers being concerned, but at the end of the day we are a public body. We are accountable. If we're behaving irresponsibly, someone needs to call us out on it (Interview 4). 
Others thought that while footage should be used for development, reflection and team review/debrief purposes it shouldn't be used in an appraisal setting:

If it was directly related to your work and it's used in a constructive format, and it's to do with professionalism, I don't think there's any issue with that, and I don't think there should be. What I would find not very pleasant would be if you were at an appraisal with 'We've been pulling your recordings, and we think on this date and time you did something wrong, so therefore you're under investigation' (Interview 5).

The use of footage to aid with reflection and development was also a point raised in the focus group, particularly with inexperienced frontline officers who could view their own footage and reflect on how they would deal with a similar situation in the future. As one officer explained:

it does show to the officers that are wearing them, if they've done something wrong, they'll look back and go 'Oh yeah, maybe shouldn't have done that, or there's another way I could have dealt with that' (Focus Group participant).

In this sense, the technology wasn't so much affecting officer behaviour at the time the camera was being worn but had the potential to affect future behaviour because of the ability to allow playback and reflection on performance. Research conducted in Norway has shown the positives of using BWV in police education and professional police development, in that it can aid with reflection and experiential learning. In one study it was noted how students using BWV for this purpose reported learning significantly more about communication and decision-making and identified mistakes in their performance to a greater degree than those in a comparison group (Phelps et al., 2018). This is therefore a practice which should be advocated in England and Wales, although it is acknowledged that, for those officers concerned about footage being reviewed retrospectively for the purpose of performance review, the potential appears to exist for BWV to have a chilling effect of sorts which may disrupt the everyday behaviours of some officers.

Protection against complaints from the public. The second most commonly selected statement in relation to survey question nine was ' $I$ feel more confident having BWV because it protects me against public complaints' $(58.1 \%(\mathrm{n}=58))$. This seems to stress that BWV improves the confidence of officers, both in normal situations, but also in difficult ones. For example, one officer spoke about how they thought BWV covered their back: 'If things do go wrong, I can prove exactly what I did and rationalise it' (Interview 7). Another referred to it as a 'safety blanket' (Interview 8).

Knowing that the footage existed and that their 'innocence' could be proven also made complaints brought against officers much less stressful. An example of this was given by one interview participant:

I've had it personally where people have made complaints for use of force, saying they've received injuries as a result of being assaulted by police, and before that it was a bit of a worrying time because it was one word against the other, and we had to wait months to get 
these things resolved, whereas now as Body Worn is coming in, our supervisors more and more are able to review them, look at them and ... they'll show them ... to the people that are complaining about us and say 'this is the Body Worn footage that we've got. Do you still want to go ahead with your complaint?' And nine times out of ten, they'll turn around and say 'No, no,' and they'll back off (interview 9).

Supporting previous research (Jennings et al., 2014), we also found that a benefit of BWV in relation to members of the public was the view that having the cameras on could work to deescalate a situation once an individual realised that they were being recorded. In the survey $19 \%(n=23)$ of participants identified this as a benefit of BWV (Q10). This was an issue which was also raised in the focus group:

Some people, when they realise, they're being filmed, they completely change. They start in your face, and then you say you're being recorded on video, and they tend to quieten down a bit, or you get some that go the other way, going 'I don't care about the $\mathrm{f}^{* * * i n g}$ camera,' and start shouting at the camera. What I have seen from frontline officers is that when they realise, they're being filmed, they tend to try and cover their face, or they don't start all this shouting and swearing, and bigging themselves up (Focus Group participant).

Some officers explained how some people would play up further if they spotted the cameras, but this was a minority of the public.

Errors and misunderstandings. The introduction of BWV into the police area in question had however caused some problems, partly because those officers who were wearing the technology were not always following proper procedure; with this often-causing increases in other officers' and staff workloads and in some circumstances delays in a case being processed. In the majority of circumstances such errors were unintentional, although this was not always the case.

A good example of an unintentional error was forgetting to turn the camera on. Indeed, in the survey (Q11), the second statement which was selected by the most officers $(38.9 \%(n=44))$ about the disadvantages of BWV was 'I sometimes forget to turn the camera on'. An example of this was seen during one of the observations. Two response officers had been called to an incident where a drunk driver had reversed at speed out of a parking space and then, when moving forward, had smashed into several parked cars. When officers attended the scene, the man was still sat in the driver's seat of the car and there was a bottle of alcohol on the passenger seat. The officer who approached the car and dealt with the situation forgot to turn their camera on. After the event, when asked why they hadn't used the camera, they remarked that they had just forgotten, although acknowledged that it:

Would have been useful to show that when they arrived the car was locked, and suspect was sat in the driver's seat. This would have been evidence that he was in charge of the car in an intoxicated state (Ethnographic note - conversation with a police response officer). 
In relation to this, there also appeared to be some misunderstanding as to when the cameras need to be turned on and when it was appropriate to leave them off. In relation to keeping the cameras on one disclosure officer gave the following example:

I recently had an officer who went to a scene of a chap threatening them with a knife in the street, he got hold of one of the victims and put the knife up to his throat. When the officer went down to speak to the victims, she turned her body worn video on and got an account, she then turned it off and recovered the knife from the scene, but she didn't turn it back on again. I asked her "why did you not turn your body worn video on when you recovered the knife" and her answer was "it's not a crime in action." (Interview 2).

Another example taken from the observations was a failed arrest attempt at a suspect's house. The officers in attendance didn't turn their cameras on and when asked about this explained that this was not necessary because the suspect was not at home. On the basis that the officers didn't know this at the start of the attempt, the cameras should have been on.

Conversely, there were times that officers were using the technology when they shouldn't have. One PVP officer, for example, told how too many response officers were using them for sexual offences and instead of asking minimal questions, 'we've found they've started asking too many questions and almost conducting what we would do during an $\mathrm{ABE}^{4}$, (Interview 5).

Another problem, cited mainly by disclosure officers, was the fact that response officers were not always following the correct procedure in terms of recording what the footage contained and whether it had been redacted and/or marked as evidential. One disclosure officer complained that they could read a statement about an incident which did not mention that BWV had been used, but that they couldn't trust that this was actually the case. This meant that they would then spend significant amounts of time looking through all footage files to check whether the statement was true or whether the officer had just forgotten to add it to their account. Linked to this was also the niggle that some officers now believed that they no longer needed to provide full statements if there was BWV footage. It is unclear what the motivations of the officers were in these circumstances and whether these errors were due to misunderstanding or laziness. Either way, this represents a clear shift in officer behaviour, suggesting a reliance on BWV footage to alleviate the administrative burden of writing up detailed statements.

Officers whose role relied on viewing the footage also complained about the camera angles and those recording the footage not taking enough care to ensure that the cameras were pointing where they should be, were in the holder the right way up and were not obstructed by the officers clothing. Another officer wondered whether the problem was that response officers just did not realise what the cameras could and could not pick up:

they've got the camera pointing up at the ceiling and they're looking at something on the floor and expecting their video to be taking what they're looking at and it doesn't happen ... they think that it's an all-seeing eye that will capture everything that they're seeing but that isn't the case (Interview 2). 
This problem of course exacerbates the failure of officers to complete full statements in the apparent mistaken belief that BWV footage will provide a clear account of incidents captured on camera. Taken together, these procedural and technological errors add significantly to the administrative burden on some police officers and staff, most obviously disclosure officers. While the introduction of BWV has been celebrated as serving a crucial evidential purpose in some types of offending (such as domestic violence), the reality on the ground remains that individuals within the police are required to review and edit vast amounts of BWV footage in such a format as to be suitable for court proceedings. As described above, the additional burden this poses when errors occur is not to be underestimated.

Privacy. The issue of privacy was understandably something which was mentioned both in survey responses and in interviews. Comments about privacy related both to the officers who were wearing the cameras but were also made regarding the public and in particular those who were being recorded. In terms of the officers' privacy there were some concerns about remembering to turn off the camera and a few reported incidences where they had recorded themselves going to the toilet. One officer explained that when this happened you could ask for that section of footage to be cloaked and a disclosure officer similarly explained that this type of footage would always be redacted. This had meant that while many officers mentioned the need to turn cameras off before entering bathrooms, most talked about this with humour rather than having any genuine anxiety.

Perhaps an area of greater concern, however, was a reported practice where response officers were sanitising the BWV's drag back function. One of the advantages of the technology used in the study was that the cameras had a drag back function, meaning that they would automatically record 60 seconds of action immediately prior to the officer turning the camera on. This was particularly useful in dynamic situations when it was not immediately clear that the camera would need to be turned on. Once an officer recognises that the camera should be activated, the 60 seconds immediately preceding the officer switching the camera on are automatically recorded, meaning crucial sections of an incident will be recorded, such as the officers receiving a radio call. However, in some cases, officers were sanitising these 60 seconds prior to turning the cameras on to ensure that nothing inappropriate or personal was then on the footage:

Either people are having a conversation about their social life, about their home life, about what they're doing at the weekend, and police conversation is really crude and it is known for black humour, and then either people are consciously saying we need a minute before we get here and turn this on, or people will turn their cameras off and turn them back on again so that it's not dragging sixty seconds beforehand (Interview 8).

Such conversations, it was explained, however, could be critically important especially if they provided information which would help to set the context of an incident and then later explain why an officer had behaved in a particular way. This was explained in detail by a response officer: 
Sometimes, jobs over the radio sound a lot worse than they are, so if you're going to something and they're armed with a bit of glass and they're going to harm themselves, and they're saying they're going to kill themselves down the phone, and they've got firearms, and they've got knives, and they've got previous for assault on police, most of the time you're sat in the car going 'She's an idiot. I met her yesterday. She's not going to assault us. She's absolutely fine. We can manage her.' It's probably not very professional from somebody looking in, but it's that discussion you'll have in the car beforehand, and it's valuable when you get to the scene. Everything that's given to us is sterilised information, and yet we know the people and we know the area, so you're going to always have that discussion beforehand and you're always going to have that black humour as well. When you go to a really awful job, a lot of the time we're sat on the way to the job, and inside you're thinking this might get a bit nasty, but outside you're saying 'This will be a crock of shit.' That's the conversation you're having in the car, and then you're turning up and potentially it is horrendous, and then you're very aware. Once you get to that job or once something is coming over the radio, you know that that body cam is going to be reviewed, so you're never going to drag that minute back. You're risking almost missing a bit of evidence at the beginning because you feel a bit like you're being watched (Interview 8).

The reason for this practice appears to be two-fold. First to ensure that nothing personal is included on the footage (such as crude language and black humour) but also because of a fear that such footage will be used in supervision/appraisal (see above). The first reason appears to be valid as one disclosure officer stated:

We get a lot of officers who forget that they've turned the body worn on and they're speaking as though they would... not to a member of the public but they're swearing, they're discussing their personal lives and sometimes you think "oh my god, why don't you know that you've got this on?" (Interview 2).

Such views were not shared by all officers however:

Ultimately, if you're acting in an appropriate and professional manner, there's no reason to be scared of the fact that you're recording everything because it's there to back you up from complaints... it was never seen as something that was intruding on me (Interview 6).

Others felt that it had changed their behaviour so that their privacy was not invaded:

You're more aware of the type of conversations you have maybe where if there was just myself and a colleague that I'm friends with both inside and outside of work, and we might be having a conversation. You might think twice about having that conversation if it's something to do with your personal life, or that kind of thing (Interview 5).

The introduction of BWV may also impact on public sensibilities around privacy. One officer reflected that 12 months after its introduction it was the public who noticed the cameras more than officers. This is supported by the following excerpt of ethnographic observation: 
[police receive a call from someone stating to have suicidal feelings] We [myself and the two officers] knock on the door and a man comes to open it [...] we sit on the sofa and one officer asks the man how he feels [...] The other officer explains that they are wearing video cameras, indicating with the finger the flashing circle on the BWV, and they are recording the whole conversation. The man looks like a little bit puzzled and asks "For what are you using the video? Do you want to use this against me?" The first officer without haste explains they need to activate the video camera at the start of an incident or interaction, and this is because BWV assists in providing a record of evidence and provides transparency of an encounter. "This will help us but also you as member of the public," the second officer adds [Ethnographic note - conversation with a member of public].

Despite this, in the survey $(\mathrm{Q} 13) 66.1 \%(\mathrm{n}=72)$ of respondents reported that there had been very little comment about BWV from the public. While the camera could act as a deterrent for some people in terms of deescalating a situation, a negative aspect was that it was seen as 'a bit of a barrier for somebody who's a bit worried about what they're about to disclose to you' (Interview 8). The fact that 'BWV makes members of the public less likely to approach/engage with officers' was also identified in the survey (Q11), with $23.3 \%(\mathrm{n}=26)$ of participants thinking this to be a problem.

\section{Conclusion}

In our study of one English police force, we almost unanimously found that officers were positive about the implementation of BWV into their policing practice and if given the choice would either continue to wear the cameras or continue to have access to the footage created. While this contradicts the findings in a study conducted in Florida (Headley et al., 2017), it supports the majority of other literature which argues that BWV is a valuable addition to policing (Clare et al., 2019; Coudert et al., 2015; Cubitt et al., 2017; Jennings et al., 2014; Laming, 2019). Our research also adds to the literature base concerning the impact of BWV upon the everyday behaviours of those police officers who are obliged to wear them. In some respects, there was little change in behavioural patterns, especially in terms of how officers interact with the public. However, on closer inspection two key changes were evident. Firstly, it was clear that the cameras made officers more confident in how they dealt with the public (because they were less fearful that the public would complain about them). Secondly cameras also made officers more introspective about their behaviour, leading them to ensure that they were acting professionally and appropriately when on view to the public. While this latter change in particular may be viewed as a positive consequence of the cameras, this arguably turned into a negative aspect when this additional concern as to professionalism was taken one step further and officers began to sanitise the drag back function of the camera to ensure that footage did not contain any personal or inappropriate communications with other officers. Such actions were taken not just to ensure personal privacy, but also out of fear that any inappropriate footage could be used against them in supervision meetings or appraisals. While we acknowledge that the police do need to be professional at all times, it must also be recognised that when travelling to an incident 'inappropriate' banter is often used as a coping mechanism to prepare an individual for 
what they are about to face. To either eliminate this way of coping or to make the officer fearful about later consequences is counterproductive and may negatively affect not just evidence capture but also relationships between officers and their supervisors. While emerging research on the introduction of BWV appears to champion its potential to enhance police legitimacy and procedural justice, any impacts on the everyday behaviours of officers must be carefully documented. The criticality of officer discretion during police-public encounters as well as the importance of peer support before, during and after difficult incidents are broadly accepted as fundamental pillars of policing practice. How BWV is re-shaping, disrupting or eliminating these mechanisms of everyday policing requires further research, particularly as the use of BWV becomes the norm for more police forces in England and Wales (and beyond).

\section{Declaration of conflicting interests}

The author(s) declared no potential conflicts of interest with respect to the research, authorship, and/or publication of this article.

\section{Funding}

The author(s) disclosed receipt of the following financial support for the research, authorship, and/ or publication of this article: The subject police force and also the N8PRP Staff Exchange fund [975700].

\section{ORCID iD}

Karen Harrison (D) https://orcid.org/0000-0003-1236-6301

Simone Santorso (D) https://orcid.org/0000-0002-5657-2169

\section{Notes}

1. Here we are referring to the everyday/mundane behaviour of police officers, rather than focusing on behaviour in relation to specific police tasks such as use of force, taser deployment, stop and search, etc.

2. The N8PRP Staff Exchange fund [975700].

3. Saturation occurs when adding more participants to the study does not result in obtaining additional perspectives or information.

4. Achieving Best Evidence interview.

\section{References}

Ariel B (2016) Increasing cooperation with the police using body worn cameras. Police Quarterly 19(3): 326-362.

Ariel B, Farrar W and Sutherland A (2015) The effect of police body worn cameras on use of force and citizens' complaints against the police: a randomised control trial. Journal of Quantitative Criminology 31(3): 509-535.

Ariel B, Sutherland A, Henstock D, et al. (2016a) Wearing body cameras increases assaults against officers and does not reduce police use of force: Results from a global multi-site experiment. European Journal of Criminology 13(6): 744-755. 
Ariel B, Sutherland A and Henstock D (2016b) Multi-site randomized controlled trial shows that police body-worn cameras reduce citizen's complaints against the police: a case of contagious accountability? Criminal Justice and Behaviour 12(3): 453-463.

Ariel B, Sutherland A, Henstock D, et al. (2018) The deterrence spectrum: explaining why police body-worn cameras 'work' or 'backfire' in aggressive police-public encounters. Policing: A Journal of Policy and Practice 12(1): 6-26.

Bryman A (2012) Social Research Methods. 4th edn. Oxford: Oxford University Press.

Clare J, Henstock D, McComb C, et al. (2019) The results of a randomized controlled trial of police body-worn video in Australia. Journal of Experimental Criminology 1-2. DOI: 10.1007/ s11292-019-09387-w.

College of Policing (2014) Body-Worn Video. Coventry: College of Policing Limited.

Coudert F, Butin D and Le Metayer D (2015) Body-worn cameras for police accountability: opportunities and risks. Computer Law \& Security Review 31(6): 749-762.

Cubitt T, Lesic R, Myers G, et al. (2017) Body-worn video: a systematic review of literature. Australian \& New Zealand Journal of Criminology 50(3): 379-396.

Demir M, Braga AA and Apel R (2020) Effects of police body-worn cameras on citizen compliance and cooperation: findings from a quasi-randomized controlled trial. Criminology Public Policy 19(3): 855-882.

Denzin NK (1970) The Research Act in Sociology. Chicago: Aldine.

Ferrell J and Hamm M (1998) Crime, deviance and filed research. In: Ferrell J and Hamm M (eds) Ethnography at the Edge. LINEUP, pp. 2-19.

France 24 (2019) Yellow vests: French riot police will now wear body cameras [Online] Available at: https://www.france24.com/en/20190123-yellow-vests-french-riot-police-now-wear-bodycameras (accessed 22 July 2020).

Gaub J, Choate DE, Todak N, et al. (2016) Officer perceptions of body-worn cameras before and after deployment: a study of three departments. Police Quarterly 19(3): 275-302.

Glaser BG and Strauss AL (1967) The Discovery of Grounded Theory: Strategies for Qualitative Research. Chicago, IL: Aldine.

Headley A, Gurette RT and Shariati A (2017) A field experiment of the impact of body-worn cameras on police officer behavior and perceptions. Journal of Criminal Justice 53: 102-109.

Jennings WG, Fridell LA and Lynch MD (2014) Cops and cameras: officer perceptions of the use of body-worn cameras in law enforcement. Journal of Criminal Justice 42(6): 549-556.

Kahn C (2015) Tijuana cops turn on body cameras and hope to turn off bribery [Online] Available at: https:/www.npr.org/sections/parallels/2015/03/12/392553611/with-mixed-feelilngstijuana-police-turn-on-the-body-cameras?t=1597162220578 (accessed 11 August 2020).

Kamisher E (2017) Israeli police to implement body cameras [Online] Available at: https://www.jpost. com/Israel-News/Israeli-Police-to-implement-body-cameras-496309 (accessed 11 August 2020).

Kumar S (2018) Mumbai traffic cops to wear body cameras [Online] Available at: https://www. tribuneindia.com/news/archive/nation/mumbai-traffic-cops-to-wear-body-cameras-529968 (accessed 11 August 2020).

Laming E (2019) Police use of body worn cameras. Police Practice and Research: An International Journal 20(2): 201-216.

Miller L and Toliver J and Police Executive Research Forum (2014) Implementing a Body-worn Camera Program: Recommendation and Lessons Learned. Washington DC: Community Orientated Policing Services. 
Phelps J, Strype J, Bellu SL, et al. (2018) Experiential learning and simulation-based training in Norwegian police education: examining body-worn video as a tool to encourage reflection. Policing: A Journal of Policy and Practice 12(1): 50-65.

Ready JT and Young JT (2015) The impact of on-officer video cameras on police-citizen contacts: Findings from a controlled experiment in Mesa, AZ. Journal of Experimental Criminology 11(3): 445-458.

Spencer D and Cheshire R (2017) Ten years of body worn video in Northamptonshire police. Policing 12(1): 116-119.

Yokum D, Ravishankar A and Coppock A (2017) Evaluating the Effects of Police Body-Worn cameras: A Randomised Controlled Trial. Washington, DC: The LAB @ DC. 